\title{
Endoscopic Treatment of Hypothalamic Hamartomas
}

\author{
Kyu Won Shim, M.D., Ph.D., Eun Kyung Park, M.D., M.S., Dong-Seok Kim, M.D., Ph.D. \\ Department of Pediatric Neurosurgery, Severance Children's Hospital, Yonsei University College of Medicine, Brain Korea 21 Project for \\ Medical Science, Seoul, Korea
}

Hypothalamic hamartoma $(\mathrm{HH})$ is a benign indolent lesion despite the presentation of refractory epilepsy. Behavioral disturbances and endocrine problems are additional critical symptoms that arise along with $\mathrm{HHs}$. Due to its nature of generating epileptiform discharge and spreading to cortical region, various management strategies have been proposed and combined. Surgical approaches with open craniotomy or endoscopy, stereotactic approaches with radiosurgery and gamma knife surgery or radiofrequency thermos-coagulation, and laser ablation have been introduced. Topographical dimension and the surgeon's preference are key factors for treatment modalities. Endoscopic disconnection has been one of the most favorable options performed in treating $\mathrm{HH}$. Here we discuss presurgical evaluation, patient selection, surgical procedures, and complications.

Key Words : Hypothalamic hamartoma · Epilepsy · Endoscope.

\section{INTRODUCTION}

Gelastic seizure (GS) has been a well-known hypothalamic hamartoma (HH) syndrome from sessile $\mathrm{HH}$, while endocrinological disturbances ${ }^{2,6}$ and/or visual impairment may arise from pedunculated $\mathrm{HH}^{1,5}$. Compulsive bursts of laughter are a typical and classical feature of $\mathrm{GS}^{13,14)}$. Drop attacks and other secondary generalized epilepsy symptoms usually develop as the patient ages. Other types of seizure, cognitive deterioration, and behavioral problems follow and frequently develop late in the first decade of life ${ }^{4,20)}$. It has been well known that epileptic discharge originates from the hamartoma itself and propagates to subcortical and cortical areas. Partial and generalized seizures result along with cognitive/behavioral problems, including memory deficit and mental retardation ${ }^{19,22)}$.
This rare non-neoplastic abnormal mixture of neuronal and glial tissue of the inferior hypothalamus has been postulated to be derived from the mammillo-thalamo-cingulate tract from which $\mathrm{HH}$ is networking other brain areas associated with GS or the pathway from the HH to the brainstem and cerebellum $^{16,17)}$. Recent electroencephalography-functional magnetic resonance image (EEG-fMRI) studies revealed that the ipsilateral hypothalamus, brainstem tegmentum, and contralateral cerebellum are activated. In contrast, the cunei, bilateral thalami, caudate nuclei, hippocampi, paracentral gyri, and the default mode network (precunei and inferior lateral parietal lobules) are deactivated ${ }^{36)}$. This activating network results in epileptic discharges through the premotor and frontal opercular areas (voluntary system), which are located on the same side of the broader attachment ${ }^{35)}$. This system conveys

- Received : January 5, 2017 •Revised : March 5, 2017 •Accepted : March 8, 2017

- Address for reprints : Dong-Seok Kim, M.D., Ph.D.

Department of Pediatric Neurosurgery, Severance Children's Hospital, Department of Neurosurgery, Yonsei University College of Medicine, 50-1 Yonsei-ro, Seodaemun-gu, Seoul 03722, Korea

Tel : +82-2-2228-2150, Fax : +82-2-393-9979, E-mail : dskim33@yuhs.ac

This is an Open Access article distributed under the terms of the Creative Commons Attribution Non-Commercial License (http://creativecommons.org/licenses/by-nc/4.0) which permits unrestricted non-commercial use, distribution, and reproduction in any medium, provided the original work is properly cited. 
discharges through the motor cortex and pyramidal tract to the ventral brainstem ${ }^{11,35)}$. Intralesional (inside HHs) recordings have revealed that the internal epileptiform discharges mix with low-voltage activities ${ }^{15,22,31,32)}$. Most epileptiform discharges arise from the broad attachment side ${ }^{31,32)}$. HH tissues consist of two types of neurons, small ( $90 \%$ of all $\mathrm{HH}$ neurons express glutamic acid decarboxylase) and large $\mathrm{HH}$ neurons $(\gamma$-aminobutyric acid -responsive neurons). The presence of these neurons constitute relevant evidence for ictogenesis of $\mathrm{HH}^{3,9,18,40)}$. Platinum microwire intraoperative recording of single neuron activity captured 10-20 spikes per second in over $200 \mathrm{HH}$ neurons from 14 patients. Fast-firing neurons are mostly in synchronous pairs with synchronous firing ${ }^{33}$. Electric recording through depth electrode and transendoscopic intraoperative recording are also capable of recording the epileptic activities of $\mathrm{HHs}^{21,28)}$. Therefore, concomitant scalp EEG and depth electrode recording inside HHs may be very useful in disconnecting this lesion from intractable epilepsy. The depth electrode will guide the disconnection surgery as well as confirm the successful disconnection ${ }^{28,31)}$.

Based on their shape and relationship to the hypothalamus, there are several classifications of HHs and the symptoms and severity depend on their dimensions (e.g., size, localization, type of attachment, and degree of hypothalamic displacement). Epilepsy, behavioral, and hormonal problems originate from the sessile type and precocious puberty are mostly derived from the pedunculated type ${ }^{1,34,37)}$ (Fig. 1).

In earlier studies, the seizure outcomes were found to be variable with considerable complications ${ }^{7,20,26,31)}$. However, surgical resection for total removal of HHs have led to good seizure outcomes and behavioral improvement ${ }^{10,30)}$. More favorable outcomes were guaranteed mostly from near total or total resection $^{39)}$. Favorable surgical approaches have been 'from the above' like the transcallosal interforniceal approach operation ${ }^{7,38)}$. However, 'from the above' approaches are more dangerous to the hypothalamus and adjacent structures as well as the fornix. Alternatively, endoscopic surgery, gamma knife surgery, and stereotactic radiofrequency thermo-coagulation have been introduced and presented good outcomes with fewer complications. These techniques are based on 'the disconnection' which separates HH from the 'voluntary area' to prevent propagation of epileptic discharges ${ }^{8,19,25,29,31)}$. Recently stereotactic laser ablation has been introduced and good seizure control has been achieved. Modern imaging techniques and subsequent state of the art technology in surgical image guidance systems are critical to performing this delicate $\mathrm{job}^{26}$. Since the hypothalamic area is critical itself, even though we must achieve a good seizure outcome, we should avoid critical complications. An optimal surgical approach should be selected based on the individual status of the lesion and the patient (Fig. 1).

Presurgical evaluation is very much the same as a phase 1 study for a medically intractable epilepsy patient. Routine scalp EEG monitoring and long-term video-EEG monitoring, interictal and ictal $99 \mathrm{~m}$-Tc hexamethylprophyleneamine oxime single photon emission computed tomography (SPECT), magnetic resonance imaging (MRI), neuropsychological evaluation, ophthalmological assessments with perimetry, and endocrinological investigations are included. Recent 3.0 T high resolution MRI could show the interface between $\mathrm{HH}$ and normal hypothalamus and be adopted for use in neuronavigation. Endocrine assessment would include sex hormone and growth hormone levels, thyroid function, prolactin level, and cortisol reserve with glucagon stimulation. Depth electrode insertion into the HH with EEG monitoring would provide the margin and depth of disconnection. Surgical indications are intractable GS, neurobehavioral deterioration, and the absence of a cortical lesion on MRI. Memory, endocrine function, behavior, and vision are potentially at risk after surgery $^{7,8,23,27,31)}$.

\section{Instrumentation and procedure for endoscopic surgery}

The rigid neuroendoscope used for endoscopic disconnection consists of a 30-degree Hopkins pediatric telescope (Karl Storz, Tuttlingen, Germany) with an outside diameter of 2.7 $\mathrm{mm}$, a sheath for the telescope with an outside diameter of 3.8 $\mathrm{mm}$ with two working channels, and a stylet. A monopolarcoagulating electrode or an Nd-Yag laser system, a fiberoptic light guide, an Xe light source, and an endovision system are other supporting instruments. An endoscopic procedure is performed under the general endotracheal anesthesia. Because most of the patients have small ventricles, usually a neuronavigation system is set before beginning the main surgical procedure. The AxiEM ${ }^{\mathrm{TM}}$ Electromagnetic Navigation system from Medtronic, Minneapolis, USA is usually helpful in avoiding a fixation of head. After conformation of optimal trajectory to the interface between $\mathrm{HH}$ and normal tissue un- 


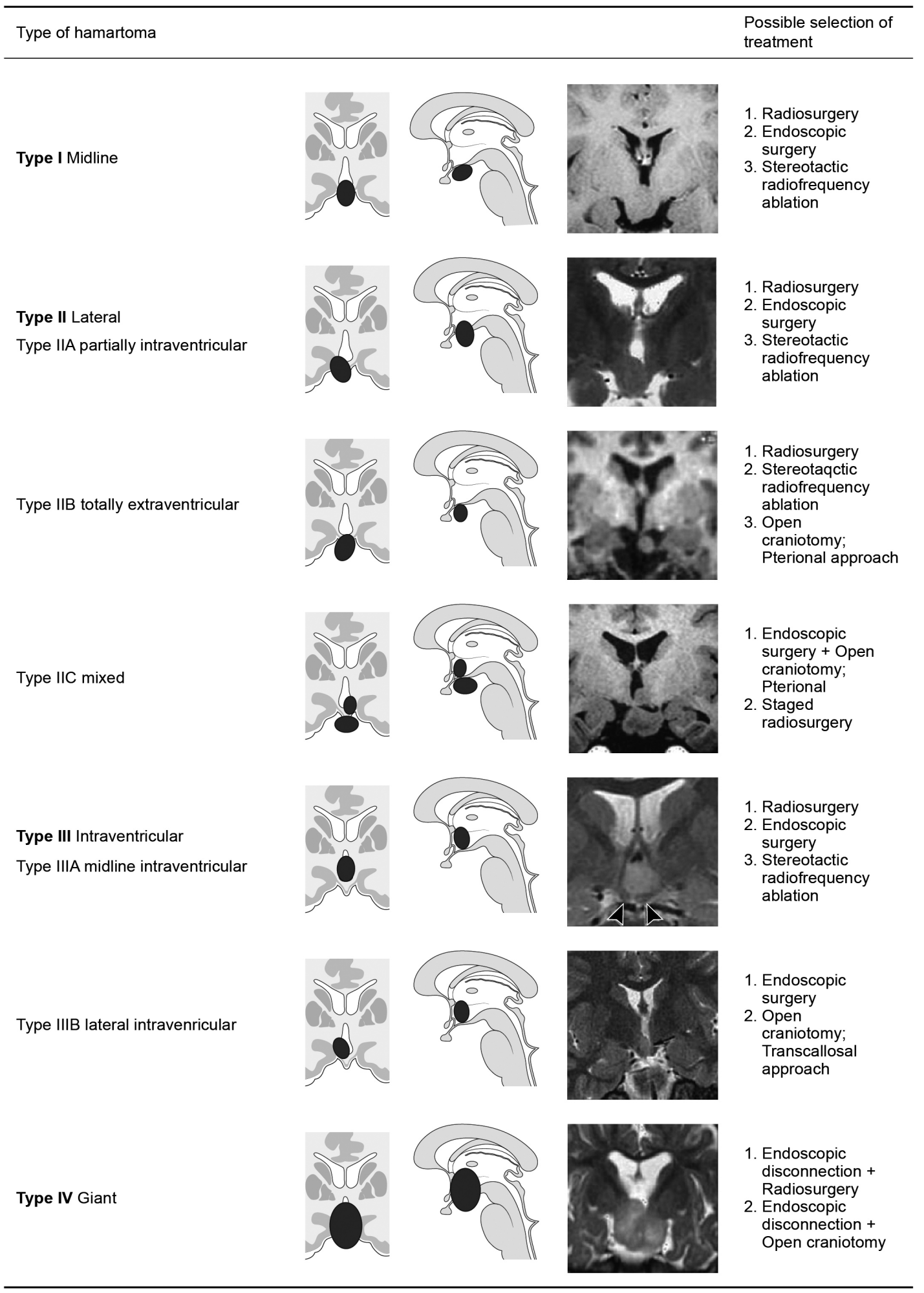

Fig. 1. Classification and possible treatment selection for hypothalamic hamartoma $(\mathrm{HH})\left(\right.$ modification from Choi et al. ${ }^{8)}$ and Delalande and Fohlen $\left.{ }^{10)}\right)$. The HHs are divided into four categories based on MR imaging findings, demonstrating the relationship between the hamartoma and hypothalamus or the third ventricle. A large hamartoma (>20 mm) is defined as a giant HH (Type IV). Small HHs (<20 mm) are classified as midline (Type I), lateral (Type II), and intraventricular (Type III) according to their location relative to the third ventricle. MR : magnetic resonance. 
der guidance of neuronavigation, Kocher's point is the most favored site for a burr hole (Fig. 2A). Then the frameless stereotaxy would be used to tap the 'normal' right lateral ventricle using a ventricular catheter (Fig. 2D). At the author's institute, a peel-away technique is usually used for endoscopic surgery. A peel-away catheter is then replaced via the tract. The telescope with the sheath is then advanced into the lateral ventricle through the peel-away catheter with irrigation of isotonic solution. When the telescope has been advanced through the foramen of Monro, the $\mathrm{HH}$ protruding from the floor and the lateral wall of the third ventricle is usually seen (Fig. 2E). The confines of the protruding hamartoma and the normal hypothalamus can be easily determined by direct visualization; however, for difficult cases, the depth electrode is inserted prior to endoscopic surgery to guide the depth and the margin of disconnection. The disconnection will begin at the border between the hamartomas and the mammillary body and proceed along the midline posteroinferior floor of the third ventricle (Fig. 2C, E, F). The direction will be posterior to anterior and lateral to inferior midline (Fig. 2A, B). Neuronavigation and the depth electrode will guide the depth of disconnection. The fiberoptic laser or monopolar coagulator is used through the working channel of the sheath. Under direct visualization, the hamartoma can be coagulated by a monopolar electric coagulator or removed by microforceps (Fig. $2 \mathrm{~A}, \mathrm{~B}, \mathrm{~F})$. When the thin pial membrane or arachnoid membrane is reached, dissection is complete. For difficult or larger/ giant $\mathrm{HH}$, dissection carries along the depth electrode until the tip of the electrode is reached. Complete disconnection between the $\mathrm{HH}$ and hypothalamus can be confirmed by observing air density along the disconnection site on postoperative brain CT scans or signal changes on MR images ${ }^{7,8)}$.

\section{Surgical outcomes}

Valdueza et al. reviewed the literature and summarized a treatment scheme according to topographical classification of $\mathrm{HHs}^{37)}$. Their classification was based on either pedunculated or sessile sagittal orientation and the treatments included open surgical removal or medicinal intervention. Furthermore, they did not suggest any treatment strategy for Type 2 sessile HHs. However, it did reveal a very important feature that sessile-type HHs usually cause GSs ${ }^{1,37)}$. Delalande et al. suggested a new classification of HHs according to their coronal relationship to the hypothalamus, and introduced 'the
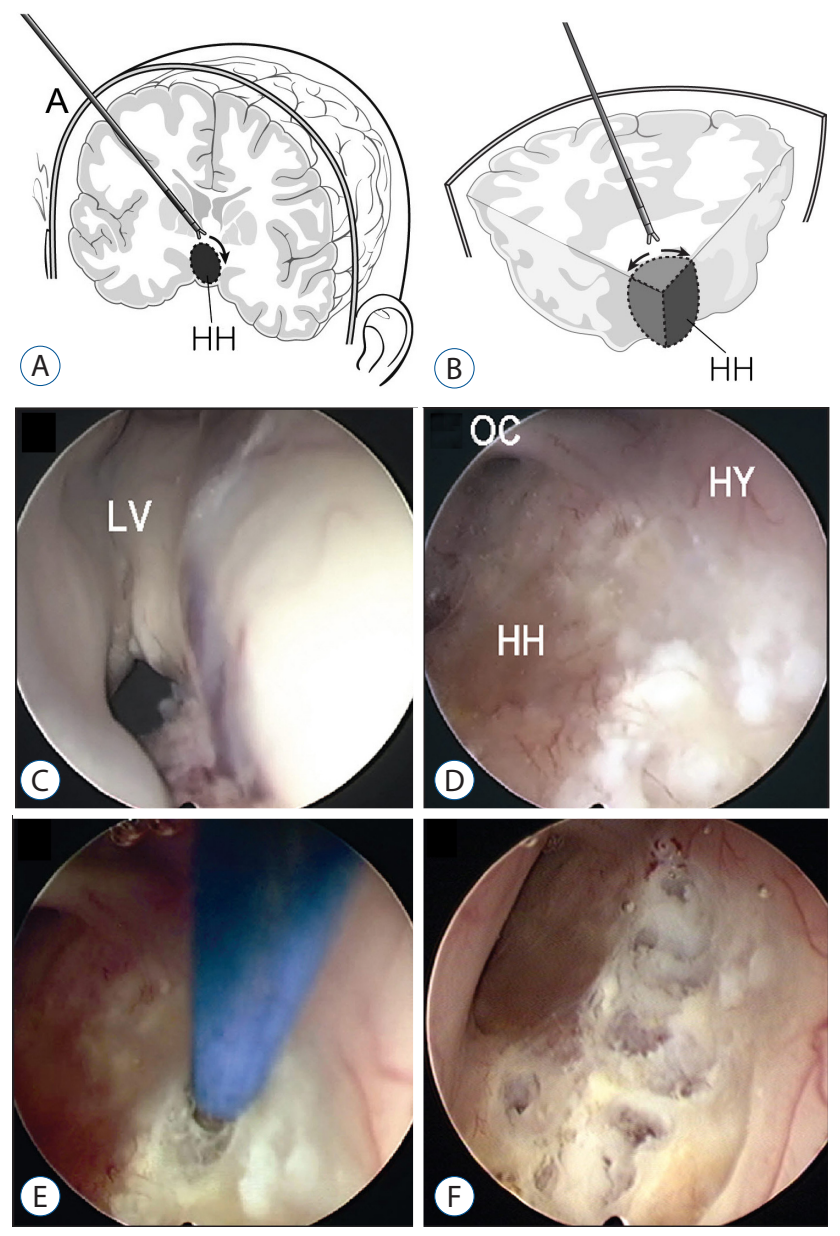

Fig. 2. Endoscopic approach to hypothalamic hamartoma (HHs). A : The trajectory to $\mathrm{HH}$ through Kocher's point. B : The direction of dissection around the lateral border of HHs. C : Relatively small ventricle and foramen of Monro. D : Discrete appearance of HHs to show the interface between $\mathrm{HH}$ and the hypothalamus. $\mathrm{E}$ : The first step of disconnection with monopolar coagulator along the lateral border of HHs. F : Disconnection of HHs from the hypothalamus with a monopolar coagulator. LV : lateral ventricle, OC : optic chiasm, HH : hypothalamic hamartoma, HY: hypothalamus.

concept of disconnection surgery for $\mathrm{HHs}^{{ }^{10,12)}}$. Their report concluded that, as hemispherectomy gave way to hemispherotomy because of serious complications, the complete removal of HHs for controlling seizures was not required anymore. As the nearby vicinity of HHs consists of very critical structures, the utmost effort should be paid to reduce collateral damage. Thus, the authors performed an endoscopic disconnection only for the intraventricular type of hamartoma (Type III). Since Choi et al. ${ }^{8}$ introduced their small series, the disconnection surgery for all types of HHs only by endoscope has been suggested as a primary treatment ${ }^{10}$. An HH smaller 
than $20 \mathrm{~mm}$ is considered small (Type I, Type II, Type III) while those larger than $20 \mathrm{~mm}$ is considered giant (Type III). Then, based on the location of the HH relative to the hypothalamus and third ventricle, additional classifications are midline (Type I), lateral (Type II), or intraventricular (Type III ${ }^{8)}$. They also performed 'repeated disconnection' for giant Type IV $\mathrm{HH}^{31)}$. These classifications have been accomplished according to the symptomatology and the feasibility of treatment modalities (Fig. 1).

Since Choi et al. and others introduced the feasibility of endoscopic disconnection as a feasible treatment option for HHs, Rekate et al. have suggested several factors for successful endoscopic disconnection as follows. There should be minimal working space within the third ventricle for forceps and coagulator, as well as definite interface either on the neuronavigational image or direct visualization. The mass should not be under the optic tract. However, most intraventricular HHs are excellent candidates for endoscopic resection or disconnection $^{8,23,27)}$. Seizure outcomes are mostly about 50-60\% of initial seizure-free condition with over $90 \%$ of seizure control (reduction of more than $50 \%$ of seizure) ${ }^{23,27,31)}$. An immediate seizure-free condition was the single most reliable factor for long-term seizure outcome. The rate of resection was not correlated to the seizure-free condition ${ }^{23)}$. Consequently, complete disconnection is considered to be more important than resection. Most small $\mathrm{HHs}$ less than $15 \mathrm{~mm}$ in diameter can be effectively managed by endoscopic disconnection ${ }^{27,31)}$. Because small HHs are often attached unilaterally, unilateral disconnection will be enough. But even though $\mathrm{HHs}$ attach to the bilateral hypothalamus, unilateral disconnection is usually enough. In bilateral attachment and giant $\mathrm{HH}$ cases, preoperative electrophysiological evaluation mostly revealed unilateral propagation of epileptiform discharge ${ }^{31,32)}$. Therefore, disconnection of the 'affected side' at first attempt is an optimal strategy for achieving a good outcome with fewer complications $^{24,31,32)}$. As the authors describe ${ }^{31)}$, even giant HHs larger than $25 \mathrm{~mm}$ can be efficiently disconnected under guidance of a depth electrode and frameless neuronavigation system. After confirmation of the extent of disconnection and seizure outcome, a second disconnection can be performed with fewer complications. Repeat endoscopic disconnection can effectively rescue the recurrence of seizure. The success rate of repeat endoscopic disconnection was reported as $50 \%{ }^{24)}$. Patients with most unilateral attachment, intraventricular type, and small HHs less than $1.5 \mathrm{~cm}$ have been reported to be very good candidates for frameless stereotactic endoscopy with over $90 \%$ good expected seizure outcome $e^{7,8,23,27,31)}$. Slitlike lateral ventricle and giant $\mathrm{HHs}$ within a 6-mm space of the third ventricle are no longer limitations in endoscopic disconnection $^{31)}$. Clear visualization of a distinct cleft or indentation and the border connecting $\mathrm{HH}$ to the hypothalamus will be the critical point for performing staged endoscopic disconnection for giant HHs. Neuronavigational neuroendoscope with a high definition visualization system will never miss the perfect entry point, trajectory, and entry for the small ventri$\mathrm{cle}^{31)}$. Complete removal of larger or giant HHs is very difficult or nearly impossible with acceptable morbidity. However, disconnection from the brain for controlling intractable epilepsy would be always feasible regardless of $\mathrm{HH}$ size.

\section{Complications}

Transient short-term memory loss, weight gain, thalamic infarction with memory loss, and hemiparesis have been reported as early complications. About 15-25\% of immediate short-term memory loss was reported while permanent memory loss was less than $10 \%(6.8-8.2 \%)^{23,27)}$. Three of four patients with postoperative disconnection-like syndrome (mental dullness, verbal anomia, unilateral tactile anomia, and lack of somesthetic transfer) were observed by Choi et al. This syndrome disappeared spontaneously within 10 days ${ }^{8)}$. Acceptable morbidity has made multiple-staged operations possible ${ }^{24,31,38)}$. A proper trajectory directly to HHs and keeping the disconnection margin straight are essential instructions for minimizing complications. An anterior wiping motion of the endoscope could result in critical damage to the fornix, optic apparatus, or hypothalamus. Because unilateral thalamic infarction can result in approximately $30 \%$ of patients by the breaching arachnoid or pia mater, staying within the third ventricle without breaching these friable membranes is of utmost importance ${ }^{23)}$. For severely affected patients, relieving intractable epilepsy would outweigh these complications and clinically significant damage to a mammillary body or fornix would not be evident. Because these patients are mostly clinically and socially impaired, pursuing resection or disconnection would be more beneficial for these patients ${ }^{38)}$. The endoscopic disconnection may not always be possible for every $\mathrm{HH}$. However, there are known factors to achieving good outcomes with minimal complications ${ }^{10,12)}$. Careful planning and 
a stepwise approach with the advanced surgical technique will make it possible ${ }^{24,31)}$.

\section{CONCLUSION}

Even though the surgeon's preference, experience, and the viewpoint will dominate the selection of a neurosurgical procedure, reasonable approaches should be selected according to the location, shape, and size of the $\mathrm{HH}^{7,31)}$. A patient's age and condition, along with factors directly related to the HHs (size and topographical dimension), must be considered in the individualized approach and plan for the staged operation. Intractable epilepsy in about $20 \%$ of patients were controlled by multiple-staged operations. Therefore, one stage operation or single modality of treatment will lose their effectiveness in managing $\mathrm{HHs}^{38)}$. Because breaking down the tract for spreading epileptiform discharge from HHs to the frontotemporal cortical region will be the optimal solution for this lesion, further aggressive maneuvers may not be necessary ${ }^{19,233}$. Thorough preoperative investigation and the use of intraoperative stereotactic and electrophysiological guidance would ensure this goal ${ }^{38)}$.

\section{References}

1. Arita K, Ikawa F, Kurisu K, Sumida M, Harada K, Uozumi T, et al. : The relationship between magnetic resonance imaging findings and clinical manifestations of hypothalamic hamartoma. J Neurosurg 91 : 212-220, 1999

2. Arroyo S, Santamaria J, Sanmarti F, Lomena F, Catafau A, Casamitjana R, et al. : Ictal laughter associated with paroxysmal hypothalamopituitary dysfunction. Epilepsia 38 : 114-117, 1997

3. Beggs J, Nakada S, Fenoglio K, Wu J, Coons S, Kerrigan JF : Hypothalamic hamartomas associated with epilepsy: ultrastructural features. J Neuropathol Exp Neurol 67 : 657-668, 2008

4. Berkovic SF, Arzimanoglou A, Kuzniecky R, Harvey AS, Palmini A, Andermann $\mathrm{F}$ : Hypothalamic hamartoma and seizures: a treatable epileptic encephalopathy. Epilepsia 44 : 969-973, 2003

5. Boyko OB, Curnes JT, Oakes WJ, Burger PC: Hamartomas of the tuber cinereum : CT, MR, and pathologic findings. AJNR Am J Neuroradiol $12: 309-314,1991$

6. Cerullo A, Tinuper P, Provini F, Contin M, Rosati A, Marini C, et al. : Autonomic and hormonal ictal changes in gelastic seizures from hypothalamic hamartomas. Electroencephalogr Clin Neurophysiol 107 : 317322,1998
7. Choi JU, Kim DS : Treatment Modalities for Intractable Epilepsy in Hypothalamic Hamartoma, in Schramm J (ed): Advances and Technical Standards in Neurosurgery. Wien : Springer, 2012, Vol 39, pp118-130

8. Choi JU, Yang KH, Kim TG, Chang JH, Chang JW, Lee BI, et al. : Endoscopic disconnection for hypothalamic hamartoma with intractable seizure. Report of four cases. J Neurosurg 100 : 506-511, 2004

9. Coons SW, Rekate HL, Prenger EC, Wang N, Drees C, Ng YT, et al. : The histopathology of hypothalamic hamartomas: study of 57 cases. J Neuropathol Exp Neurol 66 : 131-141, 2007

10. Delalande $\mathrm{O}$, Fohlen $\mathrm{M}$ : Disconnecting surgical treatment of hypothalamic hamartoma in children and adults with refractory epilepsy and proposal of a new classification. Neurol Med Chir (Tokyo) 43 : 61-68, 2003

11. DiFazio MP, Davis RG : Utility of early single photon emission computed tomography (SPECT) in neonatal gelastic epilepsy associated with hypothalamic hamartoma. J Child Neurol 15 : 414-417, 2000

12. Fohlen $M$, Lellouch $A$, Delalande 0 : Hypothalamic hamartoma with refractory epilepsy: surgical procedures and results in 18 patients. Epileptic Disord 5 : 267-273, 2003

13. Gascon GG, Lombroso CT : Epileptic (gelastic) laughter. Epilepsia 12 : 63-76, 1971

14. Gumpert J, Hansotia P, Upton A : Gelastic epilepsy. J Neurol Neurosurg Psychiatry 33 : 479-483, 1970

15. Kahane P, Ryvlin P, Hoffmann D, Minotti L, Benabid AL : From hypothalamic hamartoma to cortex: what can be learnt from depth recordings and stimulation? Epileptic Disord 5 : 205-217, 2003

16. Kameyama S, Masuda H, Murakami H : Ictogenesis and symptomatogenesis of gelastic seizures in hypothalamic hamartomas: an ictal SPECT study. Epilepsia 51 : 2270-2279, 2010

17. Khan S, Wright I, Javed S, Sharples $P$, Jardine $P$, Carter $M$, et al. : High frequency stimulation of the mamillothalamic tract for the treatment of resistant seizures associated with hypothalamic hamartoma. Epilepsia 50 : 1608-1611, 2009

18. Kim do Y, Fenoglio KA, Simeone TA, Coons SW, Wu J, Chang Y, et al. : GABAA receptor-mediated activation of $\mathrm{L}$-type calcium channels induces neuronal excitation in surgically resected human hypothalamic hamartomas. Epilepsia 49 : 861-871, 2008

19. Kuzniecky R, Guthrie B, Mountz J, Bebin M, Faught E, Gilliam F, et al. : Intrinsic epileptogenesis of hypothalamic hamartomas in gelastic epilepsy. Ann Neurol 42 : 60-67, 1997

20. Likavec AM, Dickerman RD, Heiss JD, Liow K : Retrospective analysis of surgical treatment outcomes for gelastic seizures: a review of the literature. Seizure 9 : 204-207, 2000

21. Marras CE, Rizzi M, Villani F, Messina G, Deleo F, Cordella R, et al. : Deep brain stimulation for the treatment of drug-refractory epilepsy in a patient with a hypothalamic hamartoma. Case report. Neurosurg Focus 30 : E4, 2011

22. Munari C, Kahane P, Francione S, Hoffmann D, Tassi L, Cusmai R, et al. : Role of the hypothalamic hamartoma in the genesis of gelastic fits (a video-stereo-EEG study). Electroencephalogr Clin Neurophysiol 95 : 154-160, 1995

23. Ng YT, Rekate HL, Prenger EC, Wang NC, Chung SS, Feiz-Erfan I, et al. : 
Endoscopic resection of hypothalamic hamartomas for refractory symptomatic epilepsy. Neurology 70 : 1543-1548, 2008

24. Pati S, Abla AA, Rekate HL, Ng YT : Repeat surgery for hypothalamic hamartoma in refractory epilepsy. Neurosurg Focus $30:$ E3, 2011

25. Regis J, Bartolomei F, de Toffol B, Genton P, Kobayashi T, Mori Y, et al. : Gamma knife surgery for epilepsy related to hypothalamic hamartomas. Neurosurgery 47 : 1343-1351; discussion 1351-1342, 2000

26. Rekate HL : Management of hypothalamic hamartomas: progress due to alignment of the stars. Neurosurg Focus 30 : Introduction, 2011

27. Rekate HL, Feiz-Erfan I, Ng YT, Gonzalez LF, Kerrigan JF : Endoscopic surgery for hypothalamic hamartomas causing medically refractory gelastic epilepsy. Childs Nerv Syst 22 : 874-880, 2006

28. Roberts CM, Thompson EM, Selden NR : Transendoscopic intraoperative recording of gelastic seizures from a hypothalamic hamartoma. Pediatr Neurosurg 47 : 147-151, 2011

29. Rolston JD, Chang EF : Stereotactic Laser Ablation for Hypothalamic Hamartoma. Neurosurg Clin N Am 27 : 59-67, 2016

30. Rosenfeld JV, Freeman JL, Harvey AS : Operative technique: the anterior transcallosal transseptal interforniceal approach to the third ventricle and resection of hypothalamic hamartomas. J Clin Neurosci 11 : 738-744, 2004

31. Shim KW, Chang JH, Park YG, Kim HD, Choi JU, Kim DS : Treatment modality for intractable epilepsy in hypothalamic hamartomatous lesions. Neurosurgery 62 : 847-856; discussion 856, 2008

32. Specchio N, Rizzi M, Trivisano M, Fusco L, Rebessi E, Cappelletti S, et al. : Acute intralesional recording in hypothalamic hamartoma: description of
4 cases. Acta Neurol Belg 115 : 233-239, 2015

33. Steinmetz PN, Wait SD, Lekovic GP, Rekate HL, Kerrigan JF : Firing behavior and network activity of single neurons in human epileptic hypothalamic hamartoma. Front Neurol $4: 210,2013$

34. Striano S, Striano P, Cirillo S, Nocerino C, Bilo L, Meo R, et al. : Small hypothalamic hamartomas and gelastic seizures. Epileptic Disord 4 : 129-133, 2002

35. Troester M, Haine-Schlagel R, Ng YT, Chapman K, Chung S, Drees C, et al. : EEG and video-EEG seizure monitoring has limited utility in patients with hypothalamic hamartoma and epilepsy. Epilepsia 52 : 1137-1143, 2011

36. Usami K, Matsumoto R, Sawamoto N, Murakami H, Inouchi M, Fumuro T, et al. : Epileptic network of hypothalamic hamartoma: an EEG-fMRI study. Epilepsy Res 125 : 1-9, 2016

37. Valdueza JM, Cristante L, Dammann O, Bentele K, Vortmeyer A, Saeger W, et al. : Hypothalamic hamartomas: with special reference to gelastic epilepsy and surgery. Neurosurgery 34 : 949-958; discussion 958, 1994

38. Wait SD, Abla AA, Killory BD, Nakaji P, Rekate HL : Surgical approaches to hypothalamic hamartomas. Neurosurg Focus $30: E 2,2011$

39. Wethe JV, Prigatano GP, Gray J, Chapple K, Rekate HL, Kerrigan JF : Cognitive functioning before and after surgical resection for hypothalamic hamartoma and epilepsy. Neurology 81 : 1044-1050, 2013

40. Wu J, Xu L, Kim DY, Rho JM, St John PA, Lue LF, et al. : Electrophysiological properties of human hypothalamic hamartomas. Ann Neurol 58 : 371-382, 2005 